\title{
A multi-center study to evaluate the impact of germline BRCA1 and BRCA2 mutations on ovarian cancer survival
}

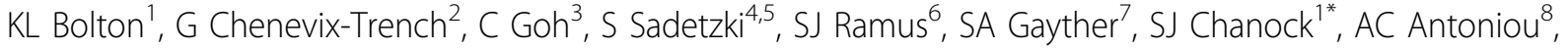 \\ PDP Pharoah ${ }^{9}$
}

From Familial Aspects of Cancer 2011 Research and Practice: A combined meeting of kConFab, Australian Breast Cancer Family Study, Australian Colorectal Cancer Family Study, Australian Ovarian Cancer Study, Family Cancer Clinics of Australia and New Zealand and kConFab

Kingscliff, Australia. 23-26 August 2011

\section{Background}

Approximately 10 percent of women with invasive epithelial ovarian cancer (EOC) carry deleterious germline mutations in BRCA1 or BRCA2. However, the impact of these mutations on ovarian cancer prognosis remains unclear.

\section{Methods}

We performed an international multi-center study of 1,470 EOC cases with pathogenic germline mutations in BRCA1 $(1,134)$ or BRCA2 (336) and 2,814 non-carriers. Our goal was to further characterize the survival of $B R C A$ carriers with EOC compared to non-carriers and to determine whether $B R C A 1$ and $B R C A 2$ carriers show similar survival patterns. Cox proportional hazards regression, both unadjusted and adjusted for other prognostic variables, was used to measure differences in overall survival during the five years following diagnosis.

\section{Results}

The five-year overall survival was 36 percent for noncarriers, 44 percent for $B R C A 1$ carriers and 52 percent for $B R C A 2$ carriers. After adjusting for study and year of diagnosis, $B R C A 1$ and BRCA2 carriers showed a more favorable survival than non-carriers $(B R C A 1, \mathrm{HR}=0.78$; 95\% $\mathrm{CI}=0.68-0.89, \mathrm{P}=2 \times 10^{-4} ; B R C A 2, \mathrm{HR}=0.61 ; 95 \%$ $\mathrm{CI}=0.50-0.76, \mathrm{P}=6 \times 10^{-6}$;). These survival differences remained after adjustment for stage, grade, histology

${ }^{1}$ Division of Cancer Epidemiology and Genetics, National Cancer Institute, Bethesda MD 20892, USA

Full list of author information is available at the end of the article and age at diagnosis (BRCA1, HR $=0.73,95 \% \mathrm{CI}=0.64$ $0.84, \mathrm{P}=2 \times 10^{-5} ; B R C A 2, \mathrm{HR}=0.49,95 \% \mathrm{CI}=0.39-0.61$, $\mathrm{P}=3 \times 10^{-10}$ ).

\section{Conclusions}

We observed a significantly improved survival in germline $B R C A 1$ and $B R C A 2$ mutation carriers with EOC compared to non-carriers. BRCA2 carriers had the most favorable outcome with a distinct clinical course from $B R C A 1$ carriers. The magnitude of the differences we observed highlight the need for clinical trials in EOC to be stratified by $B R C A 1 / 2$ status and suggest that the routine testing of women presenting with high-grade serous EOC may be warranted.

\section{Author details \\ 1 Division of Cancer Epidemiology and Genetics, National Cancer Institute, Bethesda MD 20892, USA. ${ }^{2}$ Queensland Institute of Medical Research, Locked Bag 2000, Royal Brisbane Hospital, Herston, QLD 4029, Australia. \\ ${ }^{3}$ Addenbrooke's Hospital, Hills Road, Cambridge CB2 OQQ, UK. ${ }^{4}$ Cancer and Radiation Epidemiology Unit, Gertner Institute for Epidemiology and Health Policy, Sheba Medical Center, Tel Hashomer, 52621, Israel. ${ }^{5}$ Sackler Faculty of Medicine, Tel-Aviv University, Tel-Aviv, Israel. ${ }^{6}$ Gynaecological Cancer Research Laboratories, UCL EGA Institute for Women's Health, University College London, London, UK. 'Department of Preventive Medicine, Keck School of Medicine University of Southern California, Los Angeles, California, 90033, USA. ${ }^{8}$ Centre for Cancer Genetic Epidemiology, Department of Public Health and Primary Care, University of Cambridge, Strangeways Research Laboratory, Worts Causeway, Cambridge CB1 8RN, UK. ${ }^{9}$ Cancer Research United Kingdom Department of Oncology and Department of Public Health and Primary Care, University of Cambridge, Strangeways Research Laboratory, Worts Causeway, Cambridge CB1 8RN, UK.}

Published: 12 April 2012 
doi:10.1186/1897-4287-10-S2-A27

Cite this article as: Bolton et al: A multi-center study to evaluate the impact of germline BRCA1 and BRCA2 mutations on ovarian cancer survival. Hereditary Cancer in Clinical Practice 2012 10(Suppl 2):A27.

Submit your next manuscript to BioMed Central and take full advantage of:

- Convenient online submission

- Thorough peer review

- No space constraints or color figure charges

- Immediate publication on acceptance

- Inclusion in PubMed, CAS, Scopus and Google Scholar

- Research which is freely available for redistribution

Submit your manuscript at www.biomedcentral.com/submit 